\title{
KONSEPTUALISASI SISTEM PENDIDIKAN AKHLAK MENURUT ALQURAN DAN HADIS
}

\author{
$\underline{\text { Anis Husni Firdaus }}$ \\ Institut Agama Islam Darussalam (IAID) Ciamis \\ E-mail : anishusnifirdaus@gmail.com
}

\begin{abstract}
Initially, this article describes how to reconseptualize education of akblak based on Alquran and Hadith. Philosophically, nowadays, the concept of akblak education is highly needed. Furthermore, it is grounded on the facts that philosophical thought remains unclear. The concepts or theories of Islamic Education are challenged by the development of human civilization which is marked by the alteration of values in societies related to the advanced technology and science. Moreover, it also explains how Alquran dan Hadith reforms the Islamic concept of akblak education so it could offer alternative solutions and thoughts from every akblake problems. Besides it could be a selfassessment on the weaknesses of thought.
\end{abstract}

Keywords: Akblak, Education, Alquran, Hadith

\section{PENDAHULUAN}

Persoalan pendidikan akhlak memang harus diakui bukanlah persoalan baru. Banyak ahli pendidikan dalam merumuskan konsep-konsep pendidikannya telah mengaitkan dan menjadikan moral sebagai bagian tak terpisahkan dari sistem pendidikan. Bahkan sering dikatakan bahwa terbentuknya akhlak yang baik pada subyek didik merupakan tujuan hakiki dari seluruh proses dan aktifitas pendidikan. Terdapat banyak sekali faktor yang menyebabkan kemerosotan akhlak dewasa ini, antara lain kurang tertanamnya jiwa agama pada tiap-tiap orang dalam masyarakat, pendidikan akhlak tidak terlaksana sebagaimana mestinya baik di rumah, di sekolah maupun di masyarakat, kurang adanya bimbingan untuk mengisi waktu luang dengan cara yang baik dan membawa kepada pembinaan akhlak dan lain sebagainya.

Dalam konteks pendidikan Islam, Muhammad 'Athiyah al-Abrasyi misalnya, menegaskan bahwa pendidikan akhlak merupakan ruh pendidikan Islam. Pendidikan Islam merupakan pendidikan yang berjiwa budi pekerti dan akhlak yang bertujuan untuk mencapai akhlak yang sempurna (AlAbrasyi, 1970: 1). Diikuti pula oleh pandangan 'Abdullah Nasikh Ulwan yang menyatakan bahwa pendidikan akhlak merupakan serangkaian sendi moral, keutamaan tingkah laku dan naluri yang wajib dilakukan anak didik, dibiasakan dan diusahakan sejak kecil (Ulwan, 1990: 169).

Masalah akhlak secara normatif seharusnya sudah implisit dalam setiap program pendidikan, atau dengan kalimat lain - meskipun dalam setiap satuan pelajaran telah disisipkan "pendidikan akhlak" - namun konseptualisasi sistem pendidikan akhlak secara khusus tetap diperlukan guna memberikan arah atau panduan kepada pelaku pendidikan dalam menjalankan sisetem pendidikan akhlak. Dengan demikian kajian tentang konsep pendidikan akhlak secara spesifik bukan suatu hal yang mengada-ada dan tumpang tindih (overlapping) dengan konsep pendidikan secara umum.

Oleh karena itu, urgensi pendidikan akhlak dalam pendidikan pada umumnya, dan pendidikan Islam pada khususnya, tetap menjadi persoalan yang perlu diperhatikan, sehingga 
masyarakat Islam tidak terjebak pada pola-pola pendidikan modern yang hanya mengandalkan kemajuan-kemajuan yang bersifat rasional dan material belaka, dengan mengesampingkan nilai-nilai yang bersifat moral, hanya karena tidak sesuai dengan logika ilmiah yang mereka percayai (Held, 1991: 25). Dengan demikian, jelaslah bahwa pendidikan akhlak harus menjadi jiwa dari pendidikan Islam. Karena mencapai suatu akhlak yang sempurna adalah merupakan tujuan sebenarnya dari pendidikan. Selain daripada itu, akhlak merupakan aspek fundamental dalam kehidupan seseorang, masyarakat maupun negara.

Dalam konteks pendidikan Islam, konseptualisasi sistem pendidikan akhlak secara filosofis dirasa semakin dibutuhkan, mengingat pemikiran itu dirasa kurang memadai. Hal ini didasarkan pada kenyataan masih belum jelasnya pemikiran filosofis, konsep-konsep atau teori-teori pendidikan Islam (Ma'arif, 1997: 1), dihadapkan dengan perkembangan peradaban manusia yang ditandai dengan adanya pergeseran nilai yang begitu cepat ditengah-tengah masyarakat seiring perkembangan sains dan teknologi. Dalam konteks demikian, Islam ditantang untuk mampu memberikan solusi dan pemikiran alternatif sekaligus sebagai koreksi diri atas kelemahan-kelemahan dari khazanah pemikiran yang dimiliki.

\section{TINJAUAN UMUM AKHLAK; IDENTIFIKASI PENGERTIAN AKHLAK}

Secara etimologi (lughatan) akbla $>q$ (Bahasa Arab) adalah bentuk jamak dari kata khuluq yang berarti budi pekerti, perangai, tingkah laku, atau tabiat (Ma'luf, 1989: 164). Dalam bentuk isim masdar (bentuk infinitif) berasal dari kata akblaqa-yukbliqu-ikhlaqa $>n$, sesuai dengan timbangan (wazan) $s \backslash$ ulas $\backslash i$ majid af'ala-yuf'ilu-if'a > lan yang berarti al-sajizah (perangai), al-tabi'ab (kelakuan, tabi'at, watak dasar), al'adat (kebiasaan, kelaziman), al-maru'ah (peradaban yang baik), dan al-di $>n$ (agama) (Shaliba, 1978: 539). Berakar dari kata khalaqa yang berarti menciptakan. Seakar dengan kata Khaliq (Pencipta), makbluq (yang diciptakan) dan khal (penciptaan). Kesamaan akar kata tersebut mengisyaratkan bahwa dalam akhlak tercakup pengertian terciptanya keterpaduan antara kehendak Kha $>$ liq (Tuhan) dengan perilaku makbluq (manusia). Atau dengan kata lain, tata perilaku seseorang terhadap orang lain dan lingkungannya baru mengandung nilai akhlak yang hakiki manakala tindakan atau perilaku tersebut didasarkan kepada kehendak Kha>liq (Tuhan). Dari pengertian etimologis tersebut, akhlak bukan saja merupakan tata aturan atau norma perilaku yang mengatur hubungan antar sesama manusia, tetapi juga norma yang mengatur hubungan antara manusia dengan Tuhan dan bahkan dengan alam semesta (Nasution, 1992: 164).

Secara terminologis (is \}tila $>$ han) ada beberapa definisi tentang akhlak, di antaranya yaitu:

a. Imam al-Ghazali (1989: 58):

"Akhlak adalah sifat yang tertanam dalam jiwa yang menimbulkan perbuatan-perbuatan dengan mudah, tanpa memerlukan pemikiran dan pertimbangan."

b. Ibrahim Anis (1972: 202):

"Akhlak adalah sifat yang tertanam dalam jiwa, yang dengannya lahirlah macam-macam perbuatan, baik dan buruk, tanpa membutuhkan pemikiran dan pertimbangan."

c. Abdul Karim Zaidan (1976: 75):

"(Akhlak) adalah nilai-nilai dan sifat-sifat yang tertanam dalam jiwa, yang dengan sorotan dan timbangannya seseorang dapat menilai perbuatannya baik atau buruk, untuk kemudian memilih melakukan atau meninggalkannya."

d. Ibn Miskawayh (t.t.: 25): 
"Khuluq atau akhlak adalah keadaan gerak jiwa yang mendorong untuk melakukan perbuatanperbuatan dengan tanpa memerlukan pemikiran".

Dari definisi di atas, dinyatakan bahwa akblaq atau khuluq itu adalah sifat yang tertanam dalam jiwa manusia, sehingga dia akan muncul secara spontan bilamana diperlukan, tanpa memerlukan pemikiran atau pertimbangan lebih dahulu, serta tidak memerlukan dorongan kuat dari luar. Dalam Mu'jam al-Wa $>$ s it $\{$ disebutkan min ghari $b\} a>j a b\}$ ila $>$ fikr wa ru'yah (tanpa membutuhkan pemikiran dan pertimbangan). Dalam $I b\} y a>$ 'Ulu>m al-Di $>n$ dinyatakan bahwa tas $\}$ duru al-af' $>l$ bi sub $\} u>l a b$ wa yusr, min ghairi b\}a $>$ jab \} ila $>$ fikr wa ru'yah (yang menimbulkan perbuatan-perbuatan dengan gampang dan mudah, tanpa memerlukan pemikiran dan pertimbangan) (Ilyas, 2006: 2).

Dengan memperlihatkan beberapa pendapat di atas, jelaslah bahwa akhlak merupakan kehendak dan kebiasaan manusia yang menimbulkan kekuatan-kekuatan yang sangat besar untuk melakukan sesuatu. Kehendak merupakan keinginan yang ada pada diri manusia setelah dibimbing, dan kebiasaan adalah perbuatan yang diulang-ulang sehingga mudah melakukannya. Adapun proses internalisasi akhlak seringkali didahului dengan pengenalan dan pengertian, dan setelah meresap di dalam hati kemudian mengejawantahkan dalam perbuatan. Perbuatan ini dilakukan atas kesadaran sendiri dari seseorang, tidak ada paksaan dari luar (Solihin dan Anwar, 2005: 25).

Akhlak adalah hal-hal yang berkaitan dengan sikap, perilaku dan sifat-sifat manusia dalam berinteraksi dengan dirinya, dengan sesamanya, dengan makhluk-makhluk lain dan dengan Tuhannya. Perwujudan akhlak itu bersifat spontan, dalam arti sangat mudah dan tidak memerlukan proses pemikiran dan pertimbangan yang panjang. Akhlak bukanlah semacam kemampuan (al-qudrat), juga bukan kecakapan untuk memisahkan yang baik dan yang buruk. Tetapi ia adalah keadaan jiwa yang siap untuk mewujudkan perbuatan-perbuatan baik atau buruk (El Saha dan Hadi, 2005: 41).

Adapun ilmu akhlak, menurut Mas'udi, adalah kaidah-kaidah yang digunakan untuk mengetahui kebaikan hati dan panca indera; segala ilmu yang membahas dan berkaitan dengan akhlak (Mas'udi, t.t.: 2). Sementara itu menurut Bustami dalam Mansur Ali Rajab bahwa ilmu akhlak adalah ilmu mengenai keutamaan dan cara memperolehnya serta "mencelupkannya" ke dalam pribadi, keniscayaan dan cara-cara menghindarinya (Rajab, t.t.: 13-14). Dalam Kamus al-Kaus \ar, ilmu akhlak diartikan sebagai ilmu tatakrama (Habsyi, t.t.: 87). Dan di dalam The Encyclopaedia of Islam dirumuskan pengertian ilmu akhlak sebagai berikut: It is the science of vitues and the way how to acquire them, of vices and the way how to quard against them (Gibb, 1960: 327) (Ilmu akhlak ialah ilmu tentang kebaikan dan cara mengikutinya, tentang kejahatan dan cara untuk menghindarinya). Jadi, ilmu akhlak ialah ilmu yang berusaha untuk mengenal tingkah-laku manusia kemudian memberi hukum atau nilai kepada perbuatan itu baik atau buruk sesuai dengan norma-norma akhlak dan tata susila.

Ahmad Amin memberikan definisi ilmu akhlak adalah ilmu yang menjelaskan arti baik dan buruk, menerangkan apa yang mesti diperbuat dalam pergaulan, menjelaskan tujuan yang harus dicapai, dan jalan yang sebaiknya dilalui dalam aktifitasnya (Amin, t.t.: 63). Dengan demikian, dapat dirumuskan bahwa ilmu akhlak ialah ilmu yang membahas perbuatan manusia dan mengajarkan perbuatan baik yang harus dikerjakan dan perbuatan jahat yang harus dihindari dalam pergaulannya dengan Tuhan, manusia dan makhluk (alam) sekelilingnya dalam kehidupannya sehari-hari sesuai dengan nilai-nilai moral.

\section{HUBUNGAN ANTARA ETIKA, MORAL DENGAN AKHLAK}


Hubungan antara akhlak dengan etika, moral, dan susila ini bisa dilihat dari fungsi dan perannya, yakni sama-sama menentukan nilai baik dan buruk sikap dan perbuatan manusia, sedangkan perbedaannya terletak pada standar masing-masing. Bagi akhlak standarnya adalah Alquran dan asSunnah; bagi etika standarnya pertimbangan akal pikiran; dan bagi moral standarnya adat kebiasaan yang umum berlaku di masyarakat (Asmaran, 1992: 9).

Perbedaan lain antara moral dengan etika yaitu moral adalah seperangkat aturan fundamental yang membimbing kegiatan manusia. Moralitas berisi aturan-aturan tentang perbuatan yang benar (right action) dan larangan-larangan untuk melakukan tindakan yang salah (wrong acts), sedangkan etika tidak terkait dengan aturan-aturan moral tertentu, melainkan dengan landasan-landasannya dan dengan prinsip-prinsipnya yang sangat umum untuk mengevaluasi validitas aturan moral yang ada. Karena itu bidang etika bisa berisi pembelaan dan juga kritik terhadap keyakinan atau aturan moral tertentu (Husein, 2007: 30).

Frans Magnis Suseno, membedakan ajaran moral dan etika. Ajaran moral adalah ajaranajaran, wejangan-wejangan, khutbah-khutbah, peraturan-peraturan lisan atau tulisan tentang bagaimana manusia harus hidup dan bertindak agar ia menjadi manusia yang baik. Sumber langsung ajaran moral adalah pelbagai orang dalam kedudukan yang berwenang, seperti orangtua dan guru, para pemuka masyarakat dan agama, dan tulisan para bijak. Sementara etika bukan sumber tambahan bagi ajaran moral tetapi filsafat atau pemikiran kritis dan mendasar tentang ajaran dan pandangan moral. Etika adalah sebuah ilmu dan bukan sebuah ajaran. Jadi etika dan ajaran moral tidak berada ditingkat yang sama (Suseno, 1997: 56).

Dengan demikian, etika tidak identik dengan moral atau moralitas. Namun, dalam banyak hal tidak jarang dimaksudkan sebagai hal yang identik antara etika dan moral atau moralitas; atau keduannya mempunyai sasaran - atau bahkan maksud - yang sama. Untuk lebih mempertegas mengenai pengertian ini, Frankena (1973: 5) menguraikan istilah etika sebagai berikut:

"It must be noticed, however, that the word "ethics" is not always used for this branch of philosophy; sometimes it is used as just another word for "morality", and sometimes to refer to the moral code or normative theory of an individual or group, as when I spoke earlier of "Socrates" working ethics...The terms "moral" and "ethical" are often used as equivalent to "right" or "good" and as opposed to "immoral" and "unethical".

Akhlak sangat berkaitan dengan moral. Jika pengertian agama dan moral tersebut dihubungkan satu dengan yang lainnya tampak saling berkaitan dengan erat. Dalam konteks hubungan ini jika diambil ajaran agama, maka moral adalah sangat penting bahkan yang terpenting, di mana kejujuran, kebenaran, keadilan, dan pengabdian adalah di antara sifat-sifat yang terpenting dalam agama. Hal ini sejalan dengan pendapat Fazlur Rahman yang mengatakan bahwa inti ajaran agama adalah moral yang bertumpu pada keyakinan kepercayaan kepada Tuhan (b\}abl min Alla $>$ h) dan keadilan serta berbuat baik dengan sesama (b)abl min al-na>s) (Munawwar, 2003: 30).

Tentang eratnya hubungan agama dengan moral sebagaimana tersebut di atas, dapat dianalisis dari seluruh ajaran yang terdapat dalam agama yang pada akhirnya berujung pada pembentukan moral. Perintah mengucapkan dua kalimat syahadat yang mengawali bentuk pengakuan ke-Islam-an seseorang, mengandung pesan moral agar segala ucapan dan perbuatannya dimotivasi oleh nilai-nilai yang hanya berasal dari Tuhan dan Rasul-Nya, dan sekaligus diarahkan untuk mendapatkan keridhaan-Nya. Selanjutnya mengerjakan salat ditujukan agar terhindar dari perbuatan keji dan munkar (QS. Al-Ankabut [29]: 183), aspek mengeluarkan zakat ditujukan agar menghilangkan sikap kikir dan 
menumbuhkan sikap kepedulian sosial (QS. Al-Taubah [9]: 103), dan juga pada aspek mengerjakan ibadah haji yang ditujukan agar menjauhi perbuatan keji, pelanggaran secara sengaja(fasiq) dan bermusuh-musuhan (QS. Al-Baqarah [2]: 197).

Analisa mengenai hubungan akhlak dengan moral masih dapat dilanjutkan dengan melihat seluruh pesan yang terkandung dalam ajaran Alquran. Perintah agar beriman kepada Allah SWT. yang diulang-ulang lebih dari dua ribu kali dalam Alquran ditujukan agar manusia selain mengingat Allah SWT., juga dapat menyerap sifat-sifat-Nya untuk diaplikasikan dalam kehidupan sehari-hari. Tegasnya agar manusia berakhlak atau bermoral sebagaimana moral Allah SWT., sesuai dengan kadar kesanggupan manusia. Jika Allah SWT. bersifat kasih sayang, adil, dan pemaaf, maka manusia seharusnya berusaha agar memiliki sifat-sifat yang demikian itu (Munawwar, 2003: 31).

Melalui analisis di atas, terlihat dengan jelas bahwa pendidikan agama dan akhlak memiliki hubungan yang erat. Tingkah laku yang baik antara lain dapat ditumbuhkan melalui penanaman nilainilai pendidikan agama. Diakui bahwa untuk menumbuhkan moral yang baik dapat pula diperoleh dari hasil penalaran manusia (rasio). Namun, moral yang baik akan lebih kokoh jika didasarkan pada nilainilai agama yang bersumber dari wahyu. Hal yang demikian dapat dipahami karena nilai-nilai moral yang berdasarkan agama (wahyu) memiliki nilai eskatologis, yang baik (bermoral) dalam pandangan agama bukan hanya akan mendapatkan keuntungan di dunia saja, melainkan pahala di akhirat. Pahala inilah yang lebih kuat motivasinya dalam mendorong seseorang untuk melakukan perbuatan moral. Hal ini berbeda dengan perbuatan moral yang dasarnya penalaran (rasio) di mana keuntungan yang didapat hanya keuntungan moral di dunia, tanpa adanya pahala di akhirat.

Walaupun pada dasarnya pengertian antara etika, moral dan akhlak adalah sama, namun ada juga yang membedakannya, tetapi tetap menunjuk kepada prilaku seseorang. Haedar Bagir (2002: 15) menulis dalam pengantar buku M. Amin Abdullah, Antara al-Ghazaly dan Kant: Filsafat Etika Islam, sebagai berikut:

"Etika pada umumnya diidentikkan dengan moral (atau moralitas). Namun meskipun sama terkait dengan baik-buruk tindakan manusia, etika dan moral memiliki perbedaan pengertian. Secara singkat, jika moral lebih condong kepada pengertian "nilai baik dan buruk dari setiap perbuatan manusia itu sendiri”, maka etika berarti "ilmu yang mempelajari tentang baik dan buruk". Jadi, bisa dikatakan, etika berfungsi sebagai teori dari perbuatan baik dan buruk (ethics atau 'ilm al-akblaq), dan moral (akhlak) adalah praktiknya. Dalam disiplin filsafat, terkadang etika disamakan dengan filsafat moral”.

Dari uraian di atas, dapat dikatakan bahwa antara akhlak dengan etika, moral dan susila mempunyai nuansa perbedaan sekaligus kaitan yang sangat erat. Kesemuanya mempunyai sumber dan titik berangkat yang beragam yaitu wahyu, akal, dan adat kebiasaan. Sebenarnya akal dan adat dapat dipergunakan untuk menjabarkan wahyu.

\section{KONSEP DASAR PENDIDIKAN AKHLAK MENURUT ALQURAN DAN AS-SUNNAH}

Akhlak bersumber pada Alquran yang tidak diragukan lagi keasliannya dan kebenarannya, dengan Nabi Muhammad SAW. sebagai the living Qur'an (Mansur, 2005: 224). Akhlak Islam adalah sebagai alat untuk mengontrol semua perbuatan manusia, dan setiap perbuatan manusia diukur dengan suatu sumber yaitu Alquran dan as-Sunnah. Dengan demikian, manusia harus selalu mendasarkan pada Alquran dan as-Sunnah sebagai sumber akhlak. Senada dengan hal itu tepat yang dikatakan oleh Malik Badri (1979: 100-101): 
"The Holy Qur'an and the Hadith explixitly speak of a number of specific explanatory concepts or couses for individual and collective behaviour of man. In the Holy Qur'an these causes are in fact considered psycho-spiritual and sosial natural laws, sunnat-Allah".

Alquran ini merupakan ensiklopedi konsep normatif umum. Untuk memperjelas, memperluas dan menjabarkannya, baik secara konseptual maupun praktis, sumber kedua dipakai yaitu as-Sunnah. Dalam bahasa teknisnya meneladani pemikiran ulama, selama masih bersumber kepada Alquran dan as-Sunnah yang $s\} a b\} i>b\}$, atau sekurang-kurangnya tidak bertentangan langsung atau tidak langsung terhadap kedua sumber tersebut, dapat saja dipakai untuk memperluas, memperdalam, memperjelas dan memperlancar pengembangan konseptual tentang akhlak dan pengamalannya secara fungsional (Zein, dalam http://www.google. com.id/akhlak/htm: 2).

Pemikiran di atas pada hakekatnya merupakan data kesejarahan bagaimana umat yang iman kepada Alquran dan as-Sunnah bergulat dengan kedua sumber otentik tersebut. Karena itu layak juga dipertimbangkan. Sementara itu, untuk menyusun klaster dari konsep-konsep normatif akhlak yang begitu banyak termuat dalam Alquran dan as-Sunnah, sebenarnya tidak ada patokan yang baku. Namun sebagai ancar-ancar, penyusunan klaster tersebut banyak dipengaruhi oleh faktor-faktor: (1) penguasaan makna yang tersurat dan tersirat dari kedua sumber (Alquran dan as-Sunnah); (2) keluasan wawasan penyusunan klaster.

Untuk memberikan ilustrasi konkrit tentang peluang luas untuk menentukan sendiri modelmodel klaster dari konsep-konsep normatif akhlak tersebut, secara garis besar sebagai berikut. (1) alakbla>qul mab \}mu>dab\}; (2) al-akbla>qul madzmu>mab\}; (3) mababbab; (4) adab-adab (Umary, 1998: 186). Juga rumusan yang lain: (1) akhlak terhadap Allah SWT; (2) akhlak terhadap Rasulullah SAW; (3) akhlak dalam keluarga; (5) akhlak bermasyarakat; dan (6) akhlak bernegara.

Sementara itu, Muh \{ammad 'Abdulla $>$ h $\}$ Dra $>z$ (1973: 687-771) - dalam kitabnya Dustu $>r$ al-Akbla $>$ q fi $>$ al-Isla $>m$ - memberikan model-model klaster dari konsep normatif akhlak kepada lima bagian, yaitu:

1) Akhlak Pribadi (al-akbla $>q$ al-fardiyah). Terdiri dari: (a) yang diperintahkan (al-awa $>$ mir); (b) yang dilarang (an-nawa $>$ b $\}$ ); (c) yang dibolehkan (al-muba $>$ b $\} a t)$; dan (d) akhlak dalam keadaan darurat (al-mukha $>$ lafah bi al-idbt\}ira $>r$ ).

2) Akhlak Berkeluarga (al-akbla $>q$ al-usariyah). Terdiri dari: (a) kewajiban timbal balik orangtua dan anak (wa>jiba $>$ tnab $\}$ wa al-us $\} u>l$ wa al-furu $>$ ); (b) kewajiban suami isteri (wa $>$ jiba $>$ tbaina al-arwa $>$ j); dan (c) kewajiban terhadap kerabat karib (wa>jiba $>$ tnab\}wa al-aqa $>$ rib).

3) Akhlak Bermasyarakat (al-akbla $>q$ al-ijtima $>$ iyyah). Terdiri dari: (a) yang dilarang $(a l-m a b\} z u>r a>t)$; (b) yang diperintahkan (al-awa>mir); dan (c) kaedah-kaedah adab (qawa>id al-adab).

4) Akhlak Bernegara (al-akbla $>$ q al-daulab). Terdiri dari: (a) hubungan antara pemimpin dan rakyat (alala $>$ qah baina ar-rai $>$ s wa asy-sya'b); dan (b) hubungan luar negeri (al-ala $>$ qat al-kha $>$ rijiyyah).

5) Akhlak Beragama (al-akbla $>$ q al-di $>$ niyyah). Yaitu kewajiban terhadap Allah SWT. (wa $>$ jiba $>$ tnah $\} w a$ Alla $>$ b).

Alquran adalah kitab petunjuk mengenai akhlak yang murni menerangkan norma, keagamaan dan kesusilaan yang harus diikuti oleh manusia dalam kehidupan secara individu dan kolektif, sebagaimana firman Allah SWT, dalam QS. Al-Isra> [17]: 9: 
"Sesungguhnya Alquran ini memberikan petunjuk kepada (jalan) yang lurus dan memberi khabar gembira pada orang-orang mukmin yang mengerjakan amal saleh bahwa bagi mereka pahala yang besar" (Depag RI, 1986: 425-426).

Ayat ini menjelaskan bahwa tujuan Alquran adalah memberikan petunjuk kepada manusia. Tujuan ini akan tercapai dengan memperbaiki hati dan akal manusia dengan akidah-akidah yang benar dan akhlak yang mulia, serta mengarahkan tingkah laku mereka kepada perbuatan yang baik (Aly, 1999: 32), sehingga aktualisasi nilai-nilai Alquran menjadi sangat penting, karena tanpa aktualisasi kitab suci ini, umat Islam akan menghadapi kendala dalam upaya internalisasi nilai-nilai Qur'ani sebagai upaya pembentukan pribadi umat yang beriman, bertakwa, berakhlak mulia, cerdas, maju dan mandiri (Munawwar, 2003: 7).

Menurut Rahman (1979: 34), bahwa di dalam Alquran mengandung dasar-dasar ajaran moral atau akhlak. Ajaran moral atau akhlak merupakan inti dari ajaran Alquran. Ia menulis:

"We have repeatedly emphasized that the basic elan of the Qur'an is moral and we have pointed to the ideas of social and economic justice that immediately followed from it in the Qur'an".

Di dalam tulisannya yang lain, Rahman menjelaskan bahwa ajaran moral atau akhlak tersebut menekankan pada keadilan sosial dalam bidang ekonomi dan egalitarianisme (anggapan bahwa setiap orang mempunyai kedudukan sama atau sederajat). Keadilan dan egalitarianisme ini nampak pada setiap ayat di dalam Alquran. Bahkan ajaran rukun Islam yang lima sekalipun sasaran akhirnya adalah komunitas yang berkeadilan sosial dan berprinsip egalitarianisme.

Sebagai contoh adalah salat, yang biasanya dikategorikan sebagai ibadah yang sangat murni dan juga individual. Salat diwajibkan kepada setiap Muslim, tanpa dilihat status sosialnya. Dispensasi salat, seperti rukhsah dan lain-lain, juga diberikan bukan atas dasar kedudukan sosial, namun lebih atas dasar kondisi fisik atau psikis tanpa melihat masalah status sosial, keturunan atau ekonomi. Sementara zakat jelas sekali muatan keadilan sosialnya. Memang sering nilai uang mempunyai peranan ketika bisa dijadikan alat untuk mengganti kewajiban tertentu, ketika seseorang sama sekali tidak mampu menjalankannya seperti ajaran fidyah, kaffarah, atau lainnya. Namun, itu semua bisa dipahami justru nilai keadilan sosialnya lebih kentara. Artinya, kewajiban pribadi, yang semula hanya kembali kepada pribadinya, bisa beralih menjadi kemanfaatan kepada sosial.

Sementara itu, as-Sunnah, oleh para ahli imam, disepakati sebagai sumber hukum Islam terdapat di dalam Alquran, sebagaimana difirmankan Allah SWT. dalam QS. Al-Nisa> [4]: 64:

"Dan kami tidak mengutus seorang Rasul melainkan untuk ditaati dengan seizin-Nya" (Depag RI, 1986: 425-426).

Ketentuan tersebut sejalan dengan firman Allah SWT., bahwa dalam pribadi Rasulullah SAW. terkandung akhlak mulia, yang tentunya menjadi teladan bagi umat manusia sebagaimana disebutkan dalam Q.S. Al-Qala>m [68]: 4: "Sesungguhnya engkau mempunyai budi pekerti yang lubur". Juga dalam QS. Al-Ah\}za>b [33]: 21: "Sesunggubnya telah ada pada (diri) Rasulullah SAW. itu suri tauladan yang baik bagimu'.

Jadi jelaslah bahwa hadis merupakan alternatif kedua setelah Alquran yang akan memberikan ketentuan hidup kepada manusia di dalam berbagai bidang kehidupan termasuk di dalamnya pula 
tuntunan tentang pendidikan akhlak dan hubungan manusia dengan Tuhan-Nya, hubungan dengan sesama manusia dan dengan alam sekitarnya.

Alquran sebagai sumber hukum pertama dan utama, kebenarannya bersifat mutlak, karena ia merupakan wahyu yang berupa firman-firman Allah SWT., yang kebenarannya dijamin oleh Allah SWT. Sendiri (QS. Al-Hasyr [59]: 9), sedangkan as-Sunnah - sebagai sumber hukum kedua - merupakan penjelas dari Alquran. Di sinilah terletak pentingnya fungsi hadis terhadap Alquran, yakni menjelaskan yang mubham, merinci yang mujmal, membatasi yang mutlaq, mengkhususkan yang umum dan menguraikan hukum-hukum dan tujuan-tujuannya (al-Khat\}i>b, 1998: 34-35). Dengan demikian, Alquran dan hadis menjadi sumber pembentukan hukum Islam, sehingga syariat tidak mungkin dipahami tanpa merujuk pada keduanya.

Para ulama, menurut Ajja $>j$ al-Khat $\} i>b$, telah sepakat mengenai dua macam fungsi hadis terhadap Alquran, yakni sebagai penguat dan penafsir, meskipun mereka tidak sepakat mengenai fungsi ketiganya, yaitu sebagai penetap hukum menyangkut perkara-perkara yang tidak disinggung dalam Alqur'an (al-Khat\}i >b, 1998: 50). Selain itu, fungsi hadis terhadap Alquran bukan menghapus (mansu>kh) melainkan sebatas membuat perintah umum Alquran menjadi lebih khusus (Khaeruman, 2004: 4).

Dari uraian di atas, maka jelaslah bahwa Alquran selain sebagai penjelas peran as-Sunnah, juga sebagai penegas lebih lanjut tentang ketentuan yang terdapat dalam Alquran. Tanpa as-Sunnah sebagian besar isi Alquran akan tersembunyi dari mata manusia.

\section{AYAT-AYAT ALQURAN YANG BERKAITAN DENGAN AKHLAK}

Di dalam Alquran banyak terdapat ayat-ayat yang berhubungan dengan akhlak, baik berupa perintah untuk berakhlak yang baik serta pujian dan pahala yang diberikan kepada orang-orang yang mematuhi perintah itu, maupun larangan berakhlak yang buruk serta celaan dan dosa bagi orang-orang yang melanggarnya. Tidak diragukan lagi bahwa banyak ayat-ayat Alquran tentang akhlak ini membuktikan betapa pentingnya kedudukan akhlak di dalam Islam.

Ayat-ayat Alquran yang berkaitan dengan akhlak di antaranya sebagai berikut:

\begin{tabular}{|c|l|l|}
\hline No & \multicolumn{1}{|c|}{ Tema } & \multicolumn{1}{|c|}{ Keterangan dalam Alquran } \\
\hline 1 & Akhlak yang Berhubungan dengan Allah & \multicolumn{1}{|c|}{} \\
\hline & a. Mentauhidkan Allah SWT. & Q.S. Al-Ikhlāṣ [112]: 1-4 \\
\hline & b. Takwa & Q.S. Al-Nisā [4]: 1 \\
\hline & c. Berdoa & Q.S. Al-Mu'minūn [23]: 60 \\
\hline & d. Dzikrullah & Q.S. Al-Baqarah [2]: 152 \\
\hline & e. Tawakal & Q.S. Ali Imrān [3]: 28 \\
\hline 2 & Akhlak terhadap Diri Sendiri & \multicolumn{2}{|c|}{} \\
\hline & a. Sabar & Q.S. Al-Baqarah [2]: 153 \\
\hline & b. Syukur & Q.S. Luqmān [31]: 18 \\
\hline & c. Tawadhu & Q.S. Al-Taubah [9]: 119 \\
\hline & d. Benar & \multicolumn{2}{|l}{} \\
\hline 3 & Akhlak terhadap Keluarga &
\end{tabular}




\begin{tabular}{|c|c|c|}
\hline & a. Birrul wālidain & Q.S. Al-Nisā [4]: 36 \\
\hline & b. Adil terhadap saudara & Q.S. Al-Nahl [16]: 90 \\
\hline & c. Membina dan mendidik keluarga & Q.S. Al-Tahrïm [66]: 6 \\
\hline & d. Memelihara keturunan & Q.S. al-Nahl [16]: 58-59 \\
\hline 4 & \multicolumn{2}{|l|}{ Akhlak terhadap Masyarakat } \\
\hline & a. Ukhuwah/persaudaraan & Q.S. Al-Hujurāt [49]: 10 \\
\hline & b. Ta'awun & Q.S. Al-Māidah [5]: 2 \\
\hline & c. Adil & Q.S. Al-Nisā [4]: 58 \\
\hline & d. Pemurah & Q.S. Ali Imrān [3]: 134 \\
\hline & e. Pemaaf & Q.S. Ali Imrān [3]: 159 \\
\hline & f. Menepaati janji & Q.S. Al-Isrā [17]: 34 \\
\hline & g. Musyawarah & Q.S. Asy-Syūra [42]: 38 \\
\hline & h. Wasiat di dalam keluarga & Q.S. Al-'Ashr [103]: 1-3 \\
\hline 5 & \multicolumn{2}{|l|}{ Akhlak terhadap Alam } \\
\hline & $\begin{array}{l}\text { a. Memeperhatikan dan merenungkan } \\
\text { penciptaan alam }\end{array}$ & Q.S. Ali Imrān [3]: 190 \\
\hline & b. Memanfaatkan alam & Q.S. Yūnus [10]: 101 \\
\hline & c. Istighfar dan taubat & Q.S. Al-Rūm [30]: 30 \\
\hline
\end{tabular}

Islam menjadikan akhlak yang baik sebagai bukti dan buah dari ibadah kepada Allah SWT. Misalnya, salat, zakat, dan haji. Adapun ayat-ayat yang berhubungan dengan ketiganya yaitu:

a. Tentang Șalāt: QS. Al-Ankabūt [29]: 45:

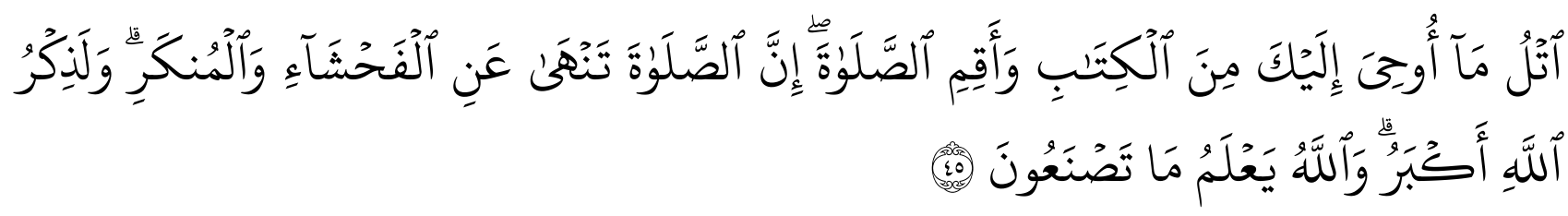

"Bacalah apa yang Telah diwahyukan kepadamu, yaitu Al Kitab (Alquran) dan Dirikanlah shalat. Sesungguhnya shalat itu mencegah dari (perbuatan- perbuatan) keji dan mungkar. dan Sesungguhnya mengingat Allah (shalat) adalah lebih besar (keutamaannya dari ibadat-ibadat yang lain). dan Allah mengetahui apa yang kamu kerjakan".

b. Tentang Zakat: QS. Al-Taubah [9]: 30:

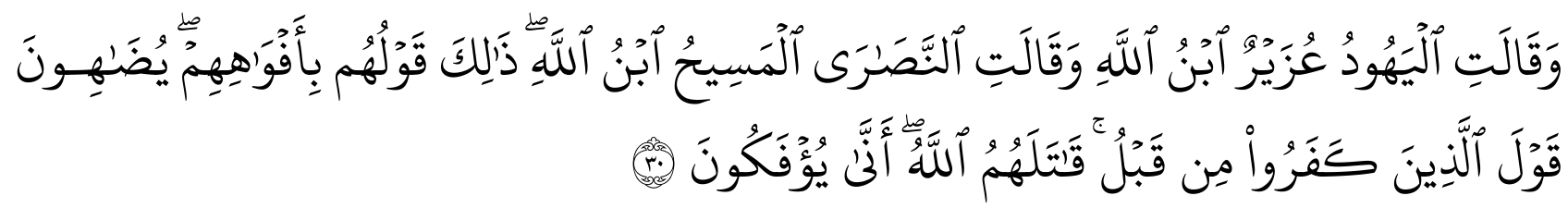

"Orang-orang Yahudi berkata: "Uzair itu putera Allah" dan orang-orang Nasrani berkata: "Al masih itu putera Allah". Demikianlah itu Ucapan mereka dengan mulut mereka, mereka meniru perkataan orang-orang kafir yang terdahulu. Dilaknati Allah mereka , bagaimana mereka sampai berpaling? 


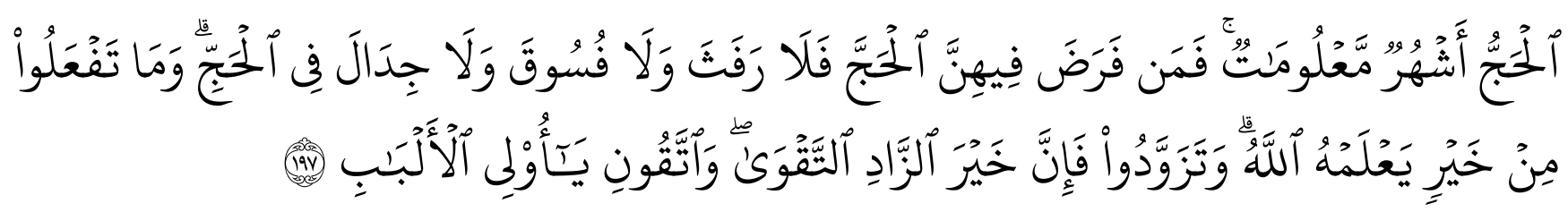

"(Musim) haji adalah beberapa bulan yang dimaklumi, barangsiapa yang menetapkan niatnya dalam bulan itu akan mengerjakan haji, Maka tidak boleh rafats, berbuat fasik dan berbantah-bantahan di dalam masa mengerjakan haji. dan apa yang kamu kerjakan berupa kebaikan, niscaya Allah mengetahuinya. Berbekallah, dan Sesungguhnya sebaik-baik bekal adalah takwa dan bertakwalah kepada-Ku Hai orang-orang yang berakal".

Dari beberapa ayat di atas, dapat dilihat adanya kaitan langsung antara salat, puasa, zakat dan haji dengan akhlak. Seorang yang mendirikan salat tentu akan mengerjakan perbuatan yang tergolong keji dan munkar. Sebab apalah arti salatnya kalau dia tetap saja mengerjakan kekejian dan kemunkaran. Seseorang yang benar-benar berpuasa demi mencari ridha Allah SWT., di samping menahan keinginannya untuk makan dan minum, tentu juga akan menahan dirinya dari segala kata-kata yang kotor dan perbuatan yang tercela, sebab tanpa meninggalkan perbuatan yang tercela itu tidak akan mendapatkan apa-apa dari puasanya kecuali dari haji, dikaitkan oleh Allah SWT hikmahnya dengan aspek akhlak.

Berkenaan dengan zakat yang disebutkan dalam ayat di atas, ada sebuah hadis yang menyatakan bahwa zakat tidak hanya terbatas pada pengeluaran harta, tetapi mencakup senyuman kepada sesama manusia, seruan kepada kebaikan dan larangan dari kejahatan, menunjukkan jalan kepada orang-orang yang tersesat, menjauhkan duri dari jalan umum, dan sebagainya.

Semua ibadah di atas dekat hubungannya dengan pendidikan akhlak, dan tujuan akhir dari pelaksanaan ibadah salat, puasa, haji, dan zakat adalah pembinaan dan pendidikan akhlak mulia. Tujuan ibadah dalam Islam dengan demikian bukanlah semata-mata menjauhkan diri dari neraka dan masuk surga, tetapi tujuan yang di dalamnya terdapat dorongan bagi kepentingan dan pembinaan akhlak yang menyangkut kepentingan masyarakat. Masyarakat yang baik dan bahagia adalah masyarakat yang para anggotanya memiliki akhlak mulia dan budi pekerti luhur.

\section{MATANHADIS YANG BERKAITAN DENGAN AKHLAK}

Dalam keseluruhan ajaran Islam, akhlak menempati kedudukan yang istimewa dan sangat penting. Hal ini bisa dilihat dari beberapa matan hadis yang berkaitan dengan akhlak, di antaranya yaitu hadis tentang "keharusan seorang yang kecil menghormati yang besar". Di dalam pembahasan redaksional hadis tersebut, penulis menggunakan metode takhrijj al-hadï yang telah digunakan oleh ulama hadis. Demikian pula halnya dalam penilaian hadis. Setelah diadakan penelusuran yang menunjukkan ke-ṣhịhh-an hadis ini, dalam kitab Mu'jam Mufahras li Alfäż al-Hadì̇ al-Nabawï, melalui kata salam (سََْْ), hadis tersebut didapati dalam kitab Șaḥịh al-Bukhārī: (Adāb: 31, 85), dan Sunan Ibnu Mājah: (Adāb: 4,5) (Wensick, 1936: 108).

Setelah dilakukan penelusuran terhadap hadis-hadis tentang seorang yang kecil menghormati yang besar - dalam kitab-kitab yang disebutkan di atas - maka didapatkan hadis tersebut yang lengkapnya sebagai berikut: 


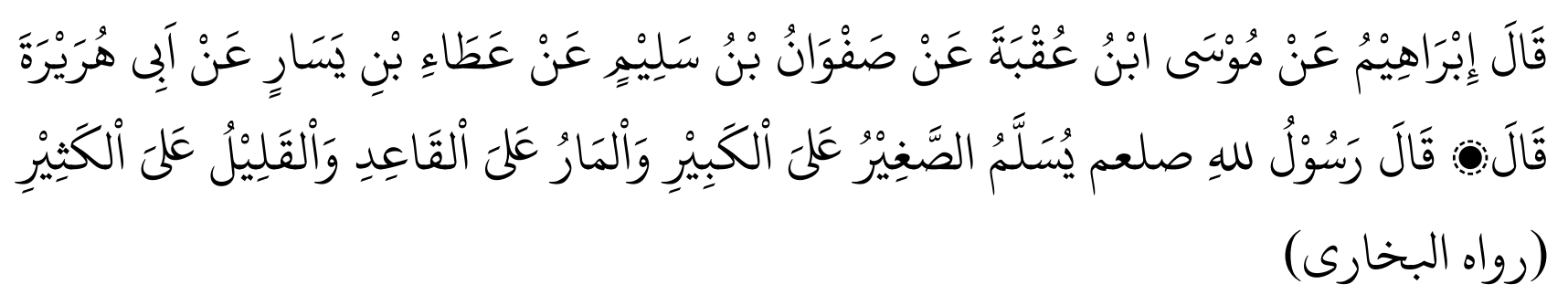

"Berkata Ibrāhīm, dari Mūsa ibn 'Uqbah, dari Șafwān ibn Salim, dari 'Atā ibn Yasār, dari Abū Hurairah berkata, bersabda Rasulullah SAW.: "Orang yang lebih muda mengucapkan salam kepada orang yang lebih tua. Orang yang lewat mengucapkan salam kepada yang duduk. Orang yang jumlahnya sedikit mengucapkan salam kepada orang yang jumlahnya lebih banyak".

Hukumnya mengucapkan salam adalah sunnah muakkadah. Sebab salam merupakan unsur pemersatu umat dan sebab timbulnya rasa kasih dan sayang antar sesama manusia. Disunnahkan anak kecil memberikan salam kepada orang dewasa (tua) dan orang yang sedikit memberi salam ke orang yang jumlahnya lebih banyak. Akan tetapi jika orang yang berhak mengucapkan salam tersebut tidak mengawali mengucapkannya (salam), maka sebaiknya orang yang tidak berhak mengawali memberi salam dahulu agar salam itu tidak sia-sia belaka. Sama halnya jika yang muda tidak memulai mengucapkan salam terlebih dahulu maka yang lebih tua sebaiknya mengucapkannya dahulu. Kemudian jika orang yang jumlahnya sedikit tidak memulai, maka kelompok orang yang banyak tersebut sebaiknya mengucapkan salam terlebih dahulu agar memperoleh pahala dan terciptanya ikatan sesama muslim harmonis. Sebagaimana dijelaskan dalam QS. Yasin: 58: "Salam, sebagai ucapan selamat dari Tuban Yang Maha Penyayang"

\section{PENUTUP}

Berdasarkan pembahasan di atas, maka dapat ditarik kesimpulan sebagai berikut: pertama, akhlak dalam Islam (baca: Alquran dan Hadis) bukanlah moral kondisional dan situasional, tetapi akhlak yang benar-benar memliki nilai yang mutlak. Nilai-nilai baik dan buruk, berlaku kapan dan di mana saja dalam segala aspek kehidupan, tidak dibatasi ruang dan waktu; kedua, konsep pendidikan akhlak yang bersumber dari wahyu Ilahi yang termaktub dalam Alquran dan Hadis merupakan pedoman bagi kehidupan umat Islam, yaitu memperoleh kebahagiaan di dunia dan akhirat; ketiga, konseptualisasi sistem pendidikan akhlak dalam satuan mata pelajaran di sekolah atau madrasah adalah suatu kenicayaan, karena konsep dasar Islam tentang akhlah terlihat arah pandang yang komperehensif; mencakup semua aspek positif perkembangan integral, intelektual, spiritual, fisik dan aspek-aspek perkembangan lainnya. Selain itu juga bersifat mendalam dan menyeluruh, tidak terikat pada suatu pandangan tertentu dan tidak bertentangan dengan teori atau filsafat pendidikan manapun; keempat, Pendidikan akhlak penting dilakukan untuk mewujudkan suatu tata kehidupan individu maupun kolektif yang bermoral bahkan dalam kaitannya dengan aspek moral manusia. Usaha pendidikan akhlak mempunyai fungsi ganda, yaitu fungsi preventif dan kuratif. Fungsi preventif mengarah pada usaha dini untuk menghiasi anak didik dengan akhlak dan mencegah dari tingkah laku yang buruk. Fungsi ini bisa dimaksimalkan pada masa pembentukan tingkah laku dan watak anak. Sedangkan fungsi kuratif mengemban misi pembenahan atau perbaikan, yaitu berusaha memperbaiki moral anak dari moral negatif menuju moral positif. 


\section{REFERENSI}

Abrasyi, Muhammad al- 'Athiyah.1970. Dasar-dasar Pokok Pendidikan Islam. Terj. Bustami dan Johar Bahry. Jakarta: Bulan Bintang.

Aly, Hery Noer. 1999. Ilmu Pendidikan Islam. Jakarta: Logos.

Amin, Ahmad. (t.t.). Kitāb Al-Akhlāq. Mesir: Dār al-Kutub al-Misriyah.

Anīs, Ibrāhīm. 1972. Al-Mu’jam al-Wāsit. Kairo: Dār al-Ma’arif.

AS, Asmaran. 1992. Pengantar Studi Akhlak. Jakarta: Rajawali Pers.

Badri, Malik B. 1979. the Dilema of Muslim Pschologists. London: MWH London Publishers.

Bagir, Haidar. 2002. Etika "Barat”, Etika Islam. Kata pengantar dalam M. Amin Abdullah. Antara al-Ghazaly dan Kant: Filsafat Etika Islam. Terj. Hamzah. Bandung: Mizan.

Depag RI. 1986. Al-Qur'an dan Terjemahannya. Jakarta: Proyek Pengadaan Kitab Suci al-Qur'an.

Drāz, Muḥammad 'Abdullāh. 1973. Dustūr al-Akhlāq fí Al-Qur'ān. Beirut: Muassasah ar-Risālah Kuwait dan Dār al-Buhusis al-'Ilmiyah.

Frankena, William K. 1973. Ethics. Englewood Cliffs, NJ: Prentice Hall.

Ghazāili, Abū Ḥamid Mụammad al-. 1989. Ihyyā 'Ulūm al-Dỉn. Juz III. Beirut: Dār al-Fikr.

Gibb, H.A.R. Et.al. 1960. Encyclopaedia of Islam. London: Luzac.

Habsyi, Husin al-. (t.t.). Kamus al-Kauśar. Surabaya: Assegaff.

Held, Virginia. 1991. Etika Moral Pembenaran Tindakan Sosial. Jakarta: Erlangga.

Husein, Machnun. 2007. "Etika Sosial dan Etika Islam”. Suara Muhammadiyah. No. 11/Tahun ke-92/1-15 Juni 2007.

Ilyas, Yunahar. 2006. Kuliah Akhlak. Cet. Ke-VIII. Yogyakarta: Lembaga Pengkajian dan Pengamalan Islam (LIPPI) Universitas Muhammadiyah Yogyakarta.

Khaeruman, Badri. 2004. Otentisitas Hadis: Studi Kritis atas Kajian Kontemporer. Bandung: Rosadakarya.

Khațīb, Mụhammad Ajjāj al-. 1998. Pokok-pokok Ilmu Hadis. Terj. M. Qadirun Nur. Jakarta: Gaya Media Pratama.

Ma'arif, Ahmad Syafi'i. 1997. “Masalah Pembaharuan Pendidikan Islam”. Dalam Ahmad Busyairi dan Azharuddin Sahl. Tantangan Pendidikan Islam. Yogyakarta: LPM UII.

Ma'luf, Luis. 1989. Kamus Al-Munjid fi al-Lughah wa al-I’lām. Beirut: Dār al-Masyriq.

Mansur. 2005. Pendidikan Anak Usia Dini dalam Islam. Yogyakarta: Pustaka Pelajar. 
Mas'ūdi, Hāfizu Ḥasan al-. (t.t.). Taisir al-Khallāq fi Ilmī al-Akhlāq. Surabaya: Salim Nahbah.

Miskawayh, Ibn. (t.t.). Tặżīb al-Akhlāq wa Tatir al-'Arāq. Mesir: Tp.

Munawar, Said Agil Husin. 2003. Aktualisasi Nilai-nilai Qur'ani dalam Sistem Pendidikan Islam. Jakarta: Ciputat Press.

Nasution. Harun. Dkk. 1992. Ensiklopedi Islam Indonesia. Jakarta: Djambatan.

Rahman, Fazlur. 1979. Islam. Chicago: The University of Chicago Press.

Saha, M. Ishom El dan Saiful Hadi. 2005. Sketsa Al-Qur'an: Tempat, Tokoh, Nama dan Istilah dalam Al-Qur'an. Cet. Ke-5. Jakarta: Lista Fariska Putra.

Shaliba, Jamil. 1978. Al-Mu'jām al-Falsafí. Juz I. Mesir: Dār al-Kitab al-Misr.

Solihin, M. dan M. Rosyid Anwar. 2005. Akhlaq Tasawuf: Manusia, Etika, dan Makna Hidup. Bandung: Nuansa.

Ulwan, Abdullah Nasikh. 1990. Pendidikan Anak Menurut Islam: Pemeliharaan Kesehatan Jiwa. Terj. Khaliluilah Ahmad Masykur. Bandung: Rema Rosda Karya.

Wensick, A.J. 1936. Mu’jam Mufahras li Alfäż al-Hadiś al-Nabawī. Juz I. Beirut: Libanon.

Zaidan, Abdul Karìm. 1976. Usūùl al-Da’wah. Baghdād: Jam’iyyah al-Amāni. 